\title{
Multiple Agent Therapy
}

National Cancer Institute

\section{Source}

National Cancer Institute. Multiple Agent Therapy. NCI Thesaurus. Code C157515.

Pharmacotherapy that uses more than one agent simultaneously. 